\title{
KETAHANAN BANGUNAN RUMAH SAKIT TERHADAP BENCANA GEMPA BUMI DI BANTUL DAERAH ISTIMEWA YOGYAKARTA
}

\author{
Dhani Gesha Gutama1, Rita Laksmitasari Rahayu² \\ ${ }^{1}$ Universitas Indraprasta PGRI, Program Studi Arsitektur \\ dhanigutama@gmail.com \\ ${ }^{2}$ Universitas Indraprasta PGRI, Program Studi Arsitektur \\ ritalaxmi@gmail.com
}

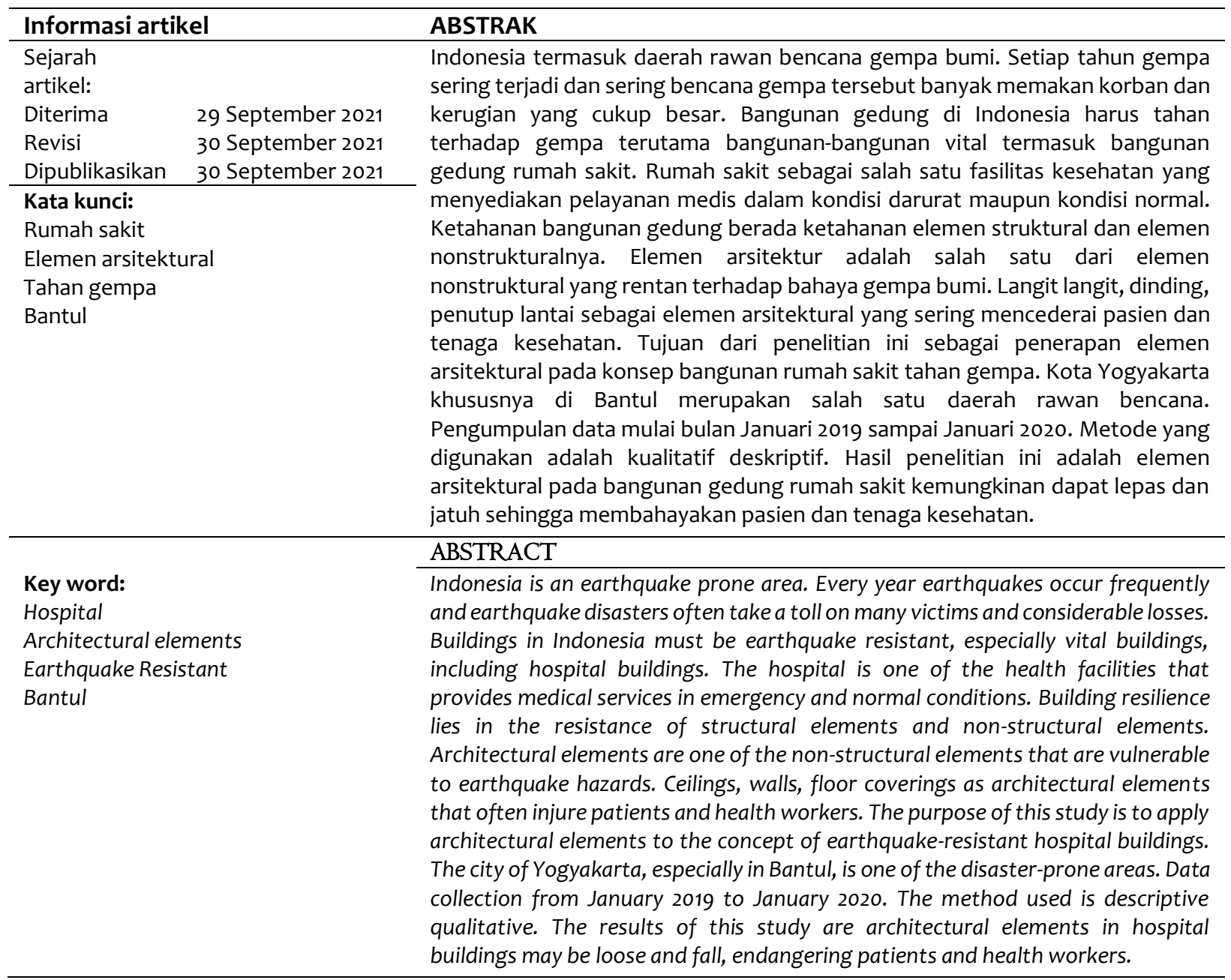

\section{PENDAHULUAN}

Indonesia terletak pada pertemuan tiga lempeng tektonik utama dunia, yaitu Lempeng Eurasia, Lempeng Indo Australia, dan Lempeng Pasifik. Ketiga lempeng ini bergerak atau bergeser hingga menumbuk, menujam, dan terjun dari satu lempeng dengan lempeng lain. Kondisi bergeraknya lempeng tersebut akan memberikan pengaruh terhadap permukaan bumi. Pergerakan tersebut yang dinamakan gempa bumi. Gempa yang dirasakan oleh manusia dipermukaan bumi tergantung dari jarak titik gempa terhadap manusia. Besar pergerakan akan mempengaruhi kemampuan bangunan di permukaan bumi. Banyak dampak berupa kerugian yang dialami oleh masyarakat akibat dari kejadian gempa bumi seperti harta benda, infrastruktur, bangunan gedung, dan juga banyak korban jiwa. Gempa bumi di Indonesia dengan kekuatan minimal magnitude 5 SR dan kedalaman kurang dari 100 km atau dalam skala Modified Mercalli Intensity (MMI) bervariasi mulai III MMI sampai VI MMI, telah 
terjadi lebih dari 185 kali selama 11 tahun terakhir (2010-2021) (BMKG, 2018). Bencana gempa bumi tidak dapat dihindari tapi harus siap untuk dihadapi dengan baik, seperti kesiapan masyarakat dalam menghadapi bencana dan bangunan gedung tahan gempa bumi. Getaran akibat dari gempa bumi menguji kinerja seluruh elemen bangunan gedung, yaitu elemen struktural bangunan dan elemen nonstruktural. Kerusakan pada bangunan gedung terjadi jika getaran (gaya luar) gempa bumi melampaui beban maksimum yang dapat direspon oleh kekakuan bangunan.

Ketika sebuah bencana menimpa sebuah komunitas atau masyarakat, semua infrastruktur ekonomi, politik, dan budaya terancam di dalam komunitas atau masyarakat itu. Semua peralatan dan fasilitas yang tersedia di masyarakat harus diberdayakan secara maksimal untuk merespons bencana (Heidaranlu, 2017). Salah satu bangunan yang harus tahan terhadap gempa adalah bangunan gedung rumah sakit. Kesiapsiagaan bangunan gedung rumah sakit penting bagi keberlangsungan kehidupan masyarakat pada masa bencana. Untuk itu rumah sakit harus memiliki aspek fisik tahan gempa baik elemen struktural dan elemen non struktural. Elemen non struktural termasuk komponen arsitektural. Salah satu aspek fisik bangunan gedung adalah komponen arsitektural, yang lebih pada penentuan sistem struktur yang sesuai dengan bentuk dan fungsi bangunan serta kaitannya dengan sistem lain dalam bangunan (Idham, 2013). Selain itu, ketahanan komponen arsitektural juga menentukan kemudahan akses seperti akses keluar dari bangunan. Kekuatan bangunan memiliki arti bangunan dapat menjadi pelindung dari bencana (Rahayu, 2020).

\section{Konsep Ketahanan Bangunan Gedung}

Bangunan gedung di Indonesia relatif kurang memperhatikan konssep ketahanan terhadap bencana terutama gempa bumi. Dampak yang dihasilkan dari bencana gempa bumi pada bangunan gedung di Indonesia memperlihatkan kesiapan ketahanan suatu bangunan gedung terhadap bencana. Konsep ketahanan bangunan gedung dimana bangunan gedung mampu menghadapi bencana gempa bumi dengan memperhitungkan kemampuan pengurangan risiko (risk reduction), kerentanan (vulnerability), pemulihan (recovery), dan resiliensi (recilience) dalam lingkup paling kecil (struktur) sampai lingkup provinsi. Waktu merespon bencana gempa mulai dari yang normal operating condition, short time: emergency response time, dan long term: reconstruction system response time (post-disaster condition). Beberapa contoh dimensi pada resiliensi adalah environmental, lifestyle and community competence, physical infrastructure, dan lainnya.

Prinsip dasar dari resiliensi adalah penggambaran kemampuan bahan untuk kembali ke bentuk aslinya setelah deformasi. Kemampuan bahan untuk kembali pada bentuk awal tergantung pada kecepatan kembali pada posisi stabil. Konsep ketahanan ini dapat diterapkan pula pada elemen arsitektural bangunan gedung dalam menghadapi bencana gempa bumi. Resiliensi adalah kemampuan dari sistem untuk bangkit kembali setelah terkena gangguan atau bencana (Cimellaro, 2010). Sebelum terjadi gempa bumi, bangunan gedung memiliki kemampuan operasional tertentu. Setelah terjadi gempa bumi, bangunan gedung mengalami penurunan kemampuan operasional. Kecepatan bangunan gedung tersebut untuk kembali beroperasi mendekati kondisi sebelum terkena bencana, dinamakan resiliensi terhadap bencana gempa. Resiliensi tidak melihat seberapa parah perubahan awal akibat suatu kejadian. Resiliensi terhadap lingkungan dari bencana, sehingga layanan "lifeline" seminimal mungkin mengalami perubahan dan dengan cepat kembali lagi pada kondisi awal (Zhong, 2013).

Pada gambar 1 terlihat kinerja elemen arsitketural saat sebelum terjadi bencana gempa bumi, bangunan gedung pada kondisi ideal yaitu: elemen arsitektural pada bangunan gedung berfungsi dan seluruh sistem bangunan berjalan dengan baik (garis a). Kinerja operasional elemen arsitektural 
bangunan gedung berada pada posisi terburuk saat bencana gempa terjadi (titik b). Posisi titik b akan tinggi atau rendah terhadap sumbu $X$ tergantung dari kekokohan bangunan gedung tersebut. Kemampuan bangunan gedung harus kembali lagi beroperasi seperti sebelum bencana gempa datang atau mendekati garis a. Kemampuan bangunan gedung tidak dapat sama atau melampaui kinerja sebelum terjadi bencana gempa, tetapi hanya dapat mendekati garis a. Kecepatan kemampuan bangunan gedung untuk beroperasi seperti sedia kala (garis a) merupakan lentingan kinerja bangunan gedung. Lentingan tersebut tergantung dari kekokohan bangunan dan kecepatan tahap pemulihan.

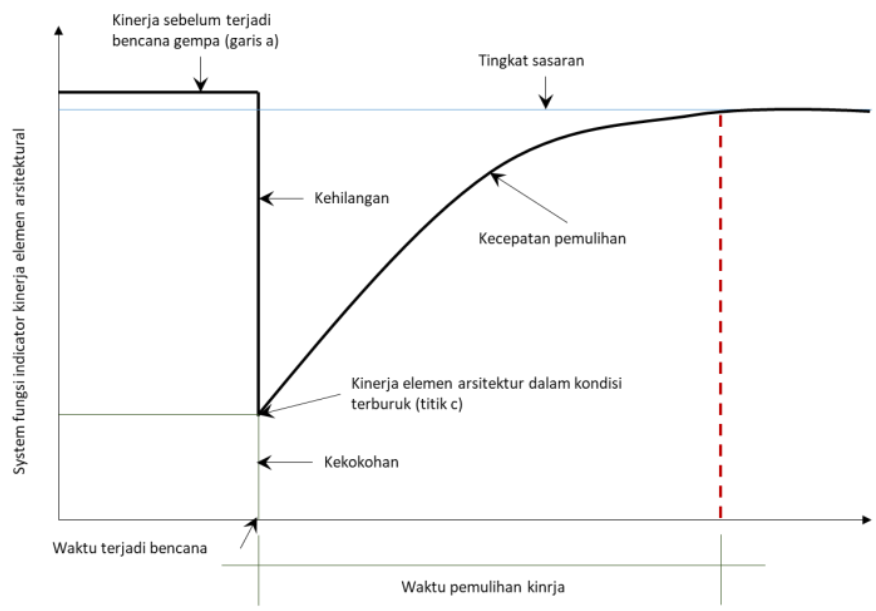

Gambar 1. Grafik ketahanan elemen arsitektural pada saat bencana dan lentingan pemulihan kinerja

Ketahanan bangunan gedung tergantung dari kekokohan bangunan (robustness) dan kesiapan untuk melakukan lentingan - waktu dan kecepatan pemulihan. Beberapa bangunan vital harus memperhatikan ketahanan bangunan gedung terhadap gempa, agar bangunan vital tersebut dapat cepat melakukan pemulihan dan berfungsi kembali dengan baik. Kekokohan bangunan dimulai dari tahap perencanaan. Pada tahap perencanaan bangunan gedung, arsitek ikut berperan pada memperhatikan kekokohan bangunan sehingga tercipta ketahanan bangunan gedung. Arsitek memperhitungkan elemen arsitektural. Arsitek dengan teliti melakukan perencanaan penggunaan komponen arsitektur seperti langit-langit, lantai, dan dinding. Tiga langkah peran arsitek pada ketahanan bangunan gedung yaitu: mengkondisikan bangunan gedung beradaptasi dengan lingkungan sehingga siap dalam kondisi bencana gempa bumi. Arsitek diharapkan mampu belajar kinerja bangunan gedung hasil rancangannya dan menggunakan hasil pelajaran tersebut pada rancangan berikutnya. Langkah ketiga adalah arsitek tetap memperhatikan kebutuhan pengguna pada hasil rancangan.

Ketahanan bangunan gedung dimulai dari pra-rancangan, penyusunan program dan perencanaan. Perencanaan menghadapi bencana dalam konteks ketahanan dimulai dari terdiri dari memperkirakan bencana yang kemungkinan terjadi pada lokasi tersebut, mencoba melakukan penilaian kerentanan lingkungan dan bangunan gedung, menganalisis dampak yang terjadi akibat bencana, membuat program ketahanan disesuaikan dengan perkiraan kerentanan bangunan gedung atau kerentanannya serta perkiraan waktu recovery, merencanakan langkah detail untuk melakukan lentingan ketahanan, memperhitungkan secara detail dari rencana langkah ketahanan, dan melakukan asesmen dari ketahanan tersebut. Tinjauan ketahanan termasuk biaya yang dibutuhkan untuk melakukan lentingan tersebut. 


\section{METODOLOGI}

Teknik pengumpulan data menggunakan wawancara, observasi langsung, dan arsip. Tujuan pengumpulan data untuk mendapatkan semua data yang terduga maupun tidak terduga, bersifat fleksibel dan mengikuti perkembangan data yang masuk. Peneliti mengumpulkan data sebanyak mungkin sampai jenuh. Pengumpulan data ini mulai bulan Januari 2019 sampai Januari 2020. Pengumpulan data pada tahap pertama berupa data literatur yang terdiri dari sumber-sumber standar yang dikeluarkan oleh Menteri Kesehatan Republik Indonesia, handbook tentang bangunan tahan gempa, standar dari WHO-Hospital Safety Index (HSI), Joint Commission International (JCI), Standar Nasional Indonesia, Standar Nasional Akreditasi Rumah Sakit (SNARS), dan data lapangan dari observasi awal penelitian. Batasan pengumpulan data adalah data kerusakan komponen arsitektur di bangunan rumah sakit. Teknik pengumpulan data menggunakan pengamatan lapangan berupa dokumentasi - foto-foto, gambar kerja jika ada.

Pemilihan obyek adalah rumah sakit umum daerah Kabupaten Bantul Daerah Istimewa Yogyakarta. Bantul merupakan daerah rawan gempa bumi yang terletak di Selatan Pulau Jawa. Peneliti melakukan pengamatan awal dan kajian Pustaka. Untuk mendapatkan data lapangan yang cukup lengkap, peneliti mendatangi beberapa rumah sakit dengan kelas, jenis rumah sakit, dan rumah sakit yang memiliki kesamaan zona rawan gempa. Latar belakang pemilihan wilayah penelitian ini sebagai berikut: Kabupaten Bantul Daerah Istimewa Yogyakarta merupakan daerah rawan bencana gempa bumi, melihat subduksi dan segmentasi subduksi berada di sisi selatan dari Pulau Jawa. Hal ini terjadi pada sepanjang Pulau Jawa bagian Selatan memiliki risiko yang lebih besar dibandingkan dengan Pulau Jawa bagian Utara.

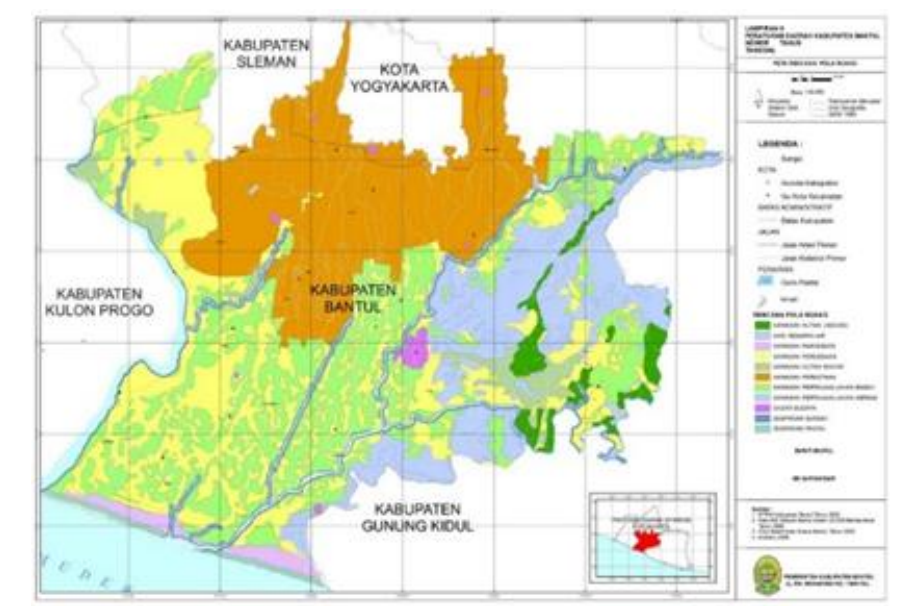

Gambar 2. Peta Kabupaten Bantul (sumber: dptr.bantulkab.go.id)

Lokasi penelitian berada di Jl. Parangtritis, Randubelang, Bangunharjo, Kecamatan Sewon, Kabupaten Bantul, Daerah Istimewa Yogyakarta 55143. Kondisi lokasi penelitian terlihat masih kosong dan belum terbangun bangunan apapun di dalamnya. Bagian depan pada lahan hanya terdapat bangunan seperti pos jaga untuk satpam yang sedang berjaga. Bagian dalam site ditumbuhi banyak tumbuhan liar yang cukup besar dan juga rumput-rumput liar yang tingginya \pm 1,5-2 meter. 


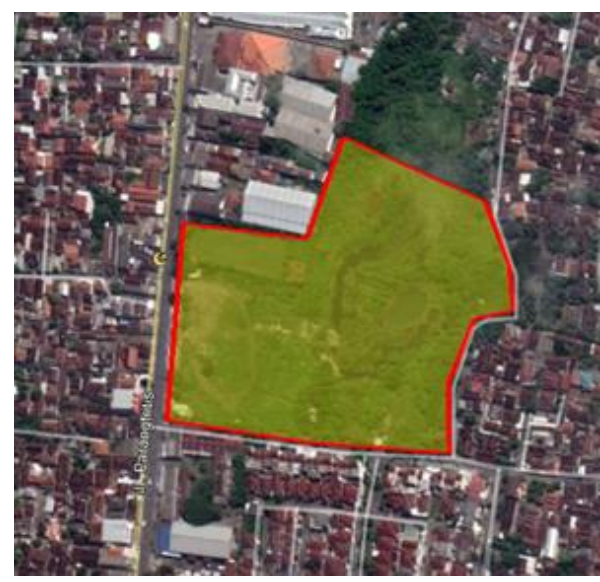

Gambar 3. Lokasi Pemilihan Lahan (sumber: google maps)
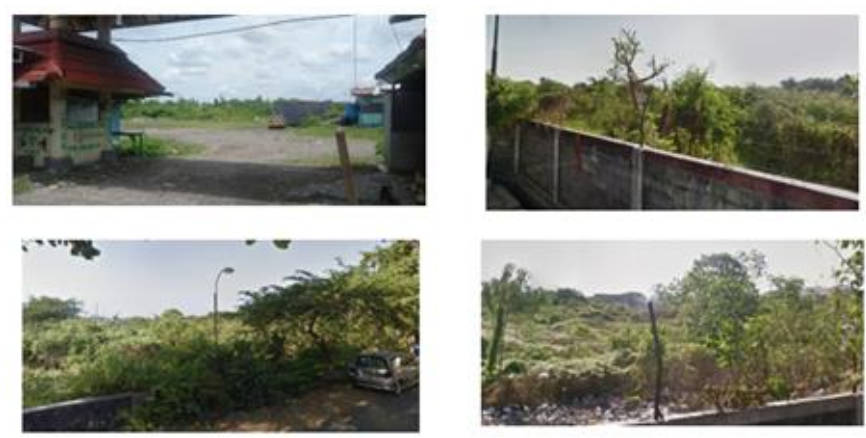

Gambar 4. Kondisi lokasi lahan (sumber: google maps)

Lokasi ini berbatasan dengan perumahan warga dan warung warung pada sebelah barat. Toko sepatu dan perumahan warga pada sebelah utara dan timur. Batas selatan berbatasan dengan bangunan rumah toko.

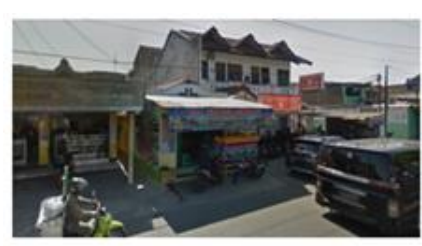

View Barat

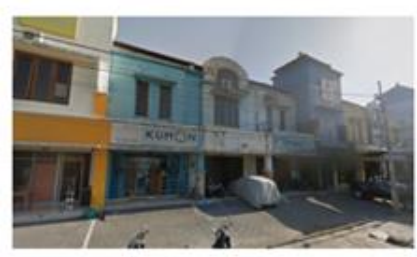

View Selatan

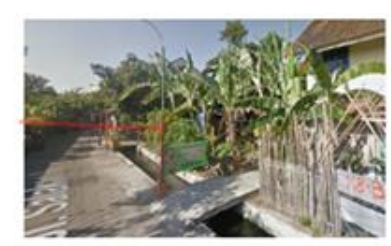

View Timur

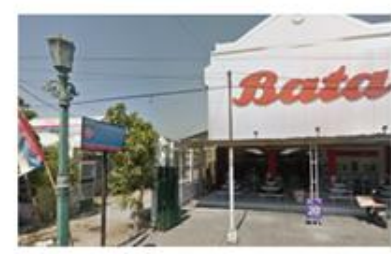

View Utara

Gambar 5. Batas batas tapak

\section{HASIL DAN PEMBAHASAN}

Hasil

Pada gambar 6 elemen non struktural yang paling rentan terhadap gempa bumi adalah komponen arsitektur $83 \%$, mechanical \& electrical $8 \%$, peralatan medis $7 \%$, dan interior $1 \%$. Kondisi kerusakan elemen non struktural yang rentan terhadap gempa bumi, yaitu: rusak, lepas, retak. Peneliti mengkategorikan menjadi 3 jenis kerusakan (gambar 6), melihat dari kemampuan elemen non 
struktural tersebut dapat digunakan Kembali setelah melakukan perbaikan. Elemen non struktural yang retak akibat gempa dapat digunakan kembali setelah dilakukan perbaikan sedang. Jenis kerusakan lepas pada elemen non struktural dapat digunakan kembali jika dilakukan perbaikan ringan

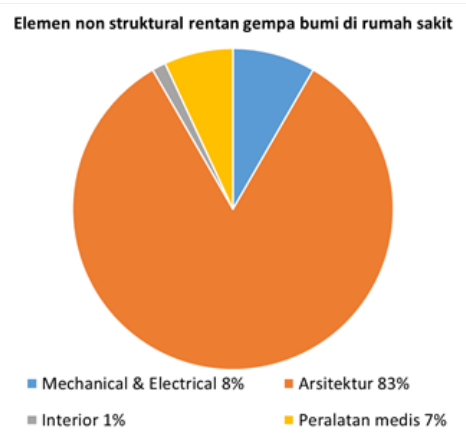

Gambar 6. Distribusi kerusakan elemen nonstruktural pada rumah sakit

Sedangkan kondisi elemen non struktural harus dilakukan perbaikan berat jika dalam kondisi rusak. Peneliti memasukkan beberapa kata kunci rusak jika ditemukan adanya elemen non struktural $80 \%$ tidak dapat digunakan kembali atau membutuhkan biaya dan waktu lama untuk memperbaikinya. Elemen non struktural memiliki tingkat kinerja yang lebih tinggi dengan membutuhkan pendekatan yang lebih dekat untuk menilai kerentanan seismik dan untuk mengembangkan strategi retrofit yang sesuai (Moghadam, 2008).

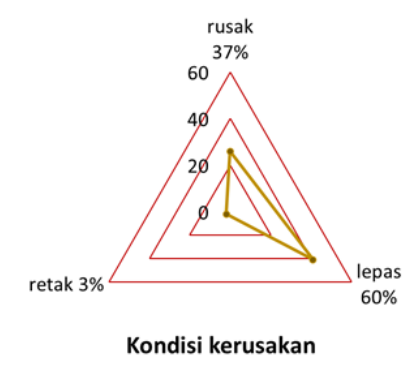

Gambar 7. Jenis kerusakan elemen nonstruktural

Pada gambar 7 terlihat jenis kerusakan elemen non struktural terbanyak dalam kondisi lepas (60\%), kondisi retak sebanyak 3\% dan rusak tidak dapat digunakan lagi sebanyak $37 \%$. Jenis kerusakan lepas membahayakan keselamatan jiwa pasien dan tenaga kesehatan.

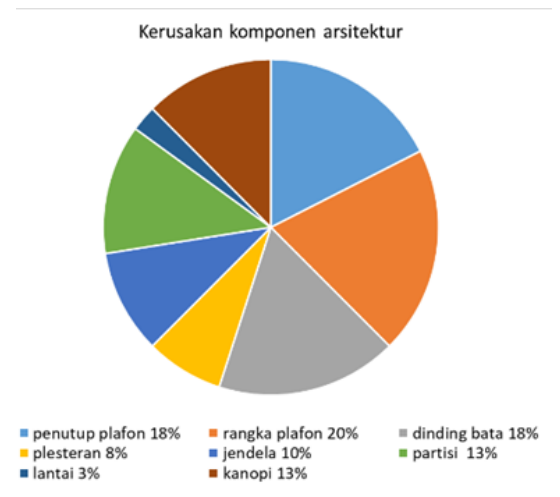

Gambar 8. Kerusakan elemen arsitektural di rumah sakit

Kerusakan komponen arsitektur terbanyak pada rangka plafon paling sering terjadi yaitu $20 \%$. Selanjutnya penutup plafon mengalami kerusakan sebanyak $18 \%$ dan kerusakan pada dinding bata $18 \%$. 
Kerusakan pada partisi dan kanopi menduduki peringkat ketiga pada kerusakan komponen arsitektur, yaitu 13\% (gambar 8 ).

\section{Pembahasan}

Kerusakan komponen arsitektur sering terjadi pada plafon baik pada penutup maupun pada rangka. Komponen arsitektural dari sebuah bangunan ini diklasifikasikan menjadi: komponen arsitektur (yaitu langit-langit, jendela dan pintu), peralatan medis dan laboratorium, lifeline (yaitu instalasi mekanis, listrik dan perpipaan) dan masalah keselamatan dan keamanan (Samsuddin, 2019).

\section{Dinding}

Sistem dinding yang digunakan pada bangunan tahan gempa memiliki ketentuan khusus baik dari segi bahan yang digunakan maupun dari segi pemasangannya di dalam bangunan. Kerusakan dinding pada bangunan sering terjadi pada bagian pertemuan dinding, pola kegagalan struktur bangunan terjadi pada sambungan balok kolom, sambungan angkur dinding dengan struktur dan konfgurasi bangunan tidak simetri (Pinondang Simanjuntak, 2020).

Besaran bukaan pintu dan jendela pada dinding dibatasi baik secara jumlah maupun ukurannya. Jumlah lebar bukaan dalam satu bidang dinding tidak boleh melebihi $1 / 2$ dari panjang dinding itu. Letak bukaan pintu/jendela juga tidak terlalu dekat dengan sudut-sudut dinding, misalnya letak minimum 2 kali tebal dinding tersebut. Kemudian, jarak antara 2 bukaan sebaiknya juga tidak kurang dari 2 kali tebal dindingnya. Ukuran pada bidang dinding juga dibatasi, misalnya tinggi maksimum 12 kali tebal dinding, dan panjangnya diantara dinding-dinding penyekat tidak melebihi 15 kali tebalnya.

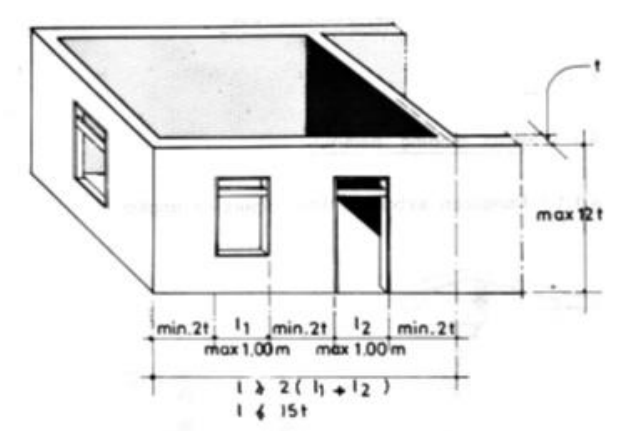

Gambar 9. Dimensi bukaan pintu jendela pada dinding (sumber: Pedoman Pembangunan Bangunan Tahan Gempa (Departemen Pekerjaan Umum)

Apabila luas dinding-dinding penyekatnya lebih besar dari ketentuan di atas, maka perlu dipasang kolom/tiang-tiang (pilaster) dinding. Kemudian blok lintel dibuat menerus keliling bangunan yang mana sekaligus berfungsi sebagai pengaku horizontal. Blok lintel tersebut perlu diikat kuat pada kolom/tiang-tiang (pilaster). 


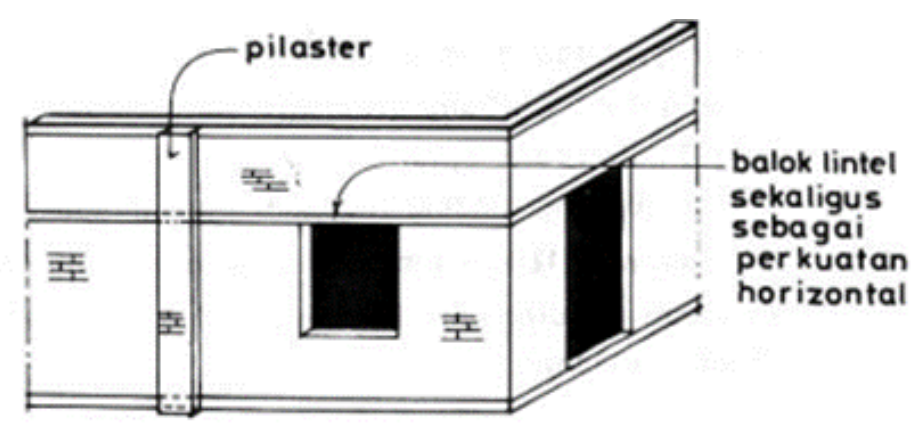

Gambar 10. Balok Lintel Sebagai Perkuatan Horizontal (sumber: Pedoman Pembangunan Bangunan Tahan Gempa (Departemen Pekerjaan Umum)

\section{Langit-langit}

Langit-langit merupakan salah satu komponen arsitektur yang paling rawan rusak atau runtuh saat gempa bumi terjadi, hal ini disebabkan karena kurangnya struktur langit langit yang berfungsi sebagai perkuatan, pemanfaatan penggantung langit langit yang dipasang pada rangka hollow langit langit sudah cukup sebagai penguatnya, yang menjadi masalah adalah jika papan gypsum pada langit langit tidak dipasang dengan baik sehingga saat gempa terjadi memungkinkan terjadinya keruntuhan, salah satu cara untuk mengikat papan gypsum pada langit langit tersebut agar tidak runtuh adalah dengan memasang dinding partisi yang tingginya mencapai langit langit, dinding partisi bertujuan sebagai elemen penyangga bagi papan gypsum tersebut.

\section{Jendela dan Pintu}

Perletakkan jendela dan pintu pada bangunan tahan gempa perlu memerhatikan ukuran dinding dan perletakannya pada dinding. Pada gambar 13 menggambarkan bahwa penempatan dinding-dinding penyekat dan bukaan pintu/jendela diusahakan sebisa mungkin simetris terhadap sumbu denah bangunan, hal ini bertujuan agar dinding serta pintu dan jendela mampu menahan gaya horizontal yang dihasilkan dari bencana gempa bumi.

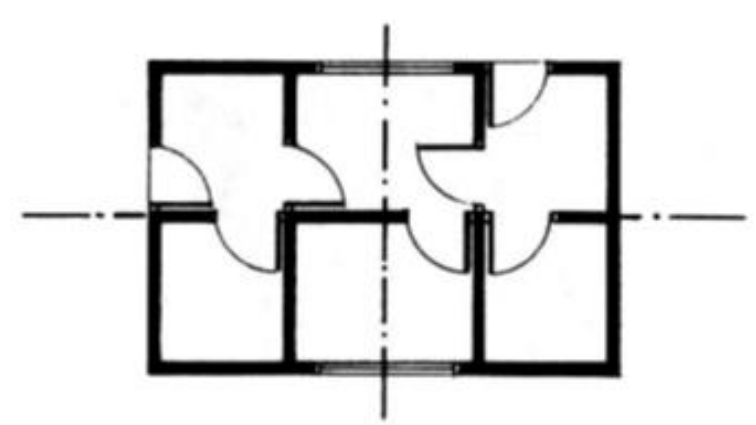

Gambar 11. Penempatan Dinding dan Pintu (sumber: Pedoman Pembangunan Bangunan Tahan Gempa (Departemen Pekerjaan Umum)

\section{Komponen Tahan Gempa Terhadap Ruang ICU Isolasi}

Ruang ICU isolasi adalah ruang yang mempunyai kekhususan secara teknis sebagai ruang perawatan intensif pasien dan memiliki batasan fisik modular per-pasien, dinding dan juga bukaan pintu jendela dengan ruangan ICU lainnya. Pada gambar 14 ruang Isolasi ini diperuntukkan bagi para pasien yang menderita penyakit menular, pasien yang menderita penyakit yang mengeluarkan bau (tumor, diabetes, ganggrein) dan juga untuk pasien yang menderita penyakit yang mengeluarkan 
suara di dalam ruangan. Pintu dan jendela di ruangan ini menggunakan partisi kaca dengan tinggi minimal $100 \mathrm{~cm}$ agar para perawat dapat memantau pasien dari luar.

Dalam hal bangunan tahan gempa, struktur bangunan yang direncanakan untuk ruangan ini adalah dengan memperhatikan layout ruangan yang sudah sesuai dengan pedoman bangunan tahan gempa, penggunaan partisi kaca cukup baik bagi dinding tersebut lantaran beban yang terikat pada dinding menjadi tidak terlalu berat, namun tidak memungkinkan saat terjadi gempa dapat terjadinya pecahan kaca akibat dari gaya horizontal yang dihasilkan oleh gempa bumi. Frame pada partisi kaca diperlukan sebagai pengikat pada dinding agar kaca tidak mudah pecah dan rubuh saat terjadi gempa bumi.

\section{KESIMPULAN DAN SARAN \\ Kesimpulan}

Berdasarkan hasil pembahasan penulis mengenai konsep ketahanan bangunan rumah sakit terhadap bencana gempa bumi di atas, penulis dapat mengambil kesimpulan sebagai berikut:

1) Resiliensi merupakan konsep penting pada suatu sistem yang kompleks dalam penanggulangan bencana. Sebelum terjadi gempa bumi, bangunan gedung memiliki kemampuan operasional tertentu yang seharusnya mampu bertahan dari gempa bumi sehingga meminimalisir kerusakan pada bangunan.

2) Kondisi kerusakan elemen non struktural yang rentan terhadap gempa bumi, dapat dikategorikan menjadi 3 yaitu: rusak, lepas, retak.

3) Total kerusakan pada komponen arsitektur yaitu sebesar $83 \%$. Komponen arsitektural yang memiliki kerusakan terbanyak yaitu ada pada rangka plafon dengan tingkat kerusakan sebesar 20\% dengan kerusakan penutup plafon 18\%, selanjutnya kerusakan terjadi pada dinding bata sebesar $18 \%$, lalu kerusakan pada partisi dan kanopi sebesar $13 \%$.

\section{SARAN/REKOMENDASI}

Bangunan tahan gempa adalah sesuatu yang harus diperhatikan oleh para ahli perancangan bangunan khususnya arsitek. Dilihat dari besarnya komponen arsitektural yang mengalami kerusakan arsitek harus memperhatikan bagaimana penggunaan material dan sistemnya sesuai dengan ketentuan standar bangunan tahan gempa yang berlaku (SNI-03-1726-2012).

\section{DAFTAR PUSTAKA}

Cimellaro, Gian Paolo, Andrei M. Reinhorn, Michel Bruneau., 2010. Seismic Resilience of a Hospital System, Structure and Infrastructure Engineering, Vol 6, 122-144

Departemen Pekerjaan Umum, Pedoman Pembangunan Tahan Gempa.

Heidaranlu, E., Khankeh. H., Ebadi, A., dan Ardalan, A.,2017. An Evaluation of Non-Structural Vulnerabilities of Hospitals Involved in the 2012 East Azerbaijan Earthquake. Trauma, 22(2): e28590 Idham, Noor Cholis., 2013. Merancang Bangunan Gedung Bertingkat Rendah, Yogyakarta, Graha Ilmu. KemenKes, R.I., 2012. Pedoman Teknis Bangunan Rumah Sakit Ruang Rawat Inap.

Komisi Akreditasi Rumah Sakit, (2018). Standar Nasional Akreditasi Rumah Sakit Edisi 1, Jakarta.

Moghadam. M.N., Moradi. S.M., Amiresmaili. M. (2017): Examining non-structural retrofitting status of teaching hospitals in Kerman against disasters, Electronic Physician, Volume: 9, Issue: 5, Pages: 4434-4439.

N.M. Samsuddin., R. Takim, A. H. Nawawi., M.R. Rosman., dan S.N.A. SyedAlwee. (2018): Non-structural Components influencing Hospital Disaster Preparedness in Malaysia, IOP Conf. Series: Earth and Environmental Science, 140, 1-10.

Pedoman Teknis Sarana Prasarana Rumah Sakit Kelas B. Kementerian Kesehatan RI Pusat Sarana, Prasarana dan Peralatan Kesehatan. 2010. Jakarta: Departemen Kesehatan.

Peraturan Menteri Kesehatan Republik Indonesia no 3 tahun 2020 tentang Klasifikasi dan Perizinan Rumah Sakit. 2020. Jakarta: Departemen Kesehatan. 
Pusat Gempa bumi dan Tsunami. (2018): Katalog Gempabumi Signifikan dan Merusak 1821-2017, Badan Meteorologi Klimatologi dan Geofisika.

Rahayu, RL, 2020. Kriteria Pemilihan Ruang Aman bagi Tenaga Kesehatan pada Saat Bencana. Jurnal Lingkungan Binaan Indonesia. Volume 9 Issue 1,. P: $31-35$ https://doi.org/10.32315/jlbi.9.1.31

Scawthorn, C., Ed. Chen Wai-Fah, 2001. Structural Engineering Handbook: Chapter 5 Earthquake Engineering, CRC Press LLC, Boca Raton, Florida.

Simanjuntak, P., 2020. Evaluasi Kerusakan Bangunan Akibat Gempa Di Indonesia. Jurnal Rekayasa Teknik Sipil dan Lingkungan-CENTECH, 1(1), pp.44-53.

Standar Nasional Indonesia 1726:2019, Tata Cara Perencanaan Ketahanan Gempa Untuk Struktur Bangunan Gedung dan Non Gedung. Badan Standardisasi Nasional. Jakarta.

WHO, dan PAHO, (2015): Hospital Safety Index: Guide for Evaluators, 2nd edition, World Health Organozation dan Pan American Health Organization, Washington D.C.

Zhong, S., Clark, M., Hou, X., Zang, Y., and Gerard, F., 2013. Proposing and Developing the Definition and Conceptual Framework for Healthcare Resilience to Cope with Disasters, Proceeding of the 9th Annual International Conference of the International Institute for Infrastructure Renewal and Reconstruction. 582-594. 